\title{
Evaluation of the FCCS crown fire potential equations in Aleppo pine (Pinus halepensis Mill.) stands in Greece
}

\author{
M. D. Schreuder ${ }^{1}$, M. D. Schaaf ${ }^{1} \&$ Da. V. Sandberg ${ }^{2}$ \\ ${ }^{1}$ Air Sciences Inc., Portland, Oregon USA \\ ${ }^{2}$ USDA Forest Service (Emeritus), Corvallis, Oregon, USA
}

\begin{abstract}
This paper evaluates the conceptual crown fire potential equations developed by Schaaf et al against observations and modelling results in Aleppo pine (Pinus halepensis Mill.) stands in Greece. The equations, integrated into the Fuel Characteristic Classification System (FCCS) in the United States, are currently used to rank the potential for passive or active crowning across a diverse set of wildland fuelbeds. The framework is based on an extension of the work by Van Wagner and Rothermel but introduces several new physical concepts to the modelling of crown fire behaviour, including the reformulated Rothermel surface fire modelling concepts proposed by Sandberg et al. A sensitivity analysis comparing the FCCS Torching Potential (TP) and Active Crown Fire Potential $(A P)$ against field observations and CFIS modelling outputs has produced encouraging results, suggesting that the FCCS crown fire potentials might be a useful tool for fire managers in the Mediterranean region to consider when evaluating the relative behaviour of crown fires in vegetated canopies.

Keywords: crown fire, crown fire potential, modelling, fire behaviour, canopy, torching, active crown fire, FCCS, aleppo pine, Mediterranean.
\end{abstract}

\section{Introduction}

The Fuel Characteristic Classification System (FCCS), [6], is a system that describes the physical characteristics of any North American wildland fuelbed, regardless of complexity, and facilitates comparisons of the physical fuelbed characteristics and fire potentials. FCCS enables the user to assess the absolute and relative effects of fuelbed differences due to natural events, fuel management 
practices, and successional changes over time. The differences can be expressed as native physical differences, such as changes in loadings and arrangements of fuelbed components; or as changes in the potential fire-related effects, such as fire behaviour or fuel consumption [5]. Until recently in FCCS, the lack of a broadly applicable and physics-based crown fire model capable of utilizing the comprehensive description of fuelbeds in FCCS hampered comparisons of the crown fire potentials among environmentally diverse fuelbeds. FCCS does not require specific predictions of crown fire behaviour across the range of fire environments but does require a relative ranking of crown fire potential over the range of wildland fuelbed characteristics. To this end, a conceptual model of crown fire initiation and spread was developed and eventually integrated into the system [1].

The body of literature advancing the science of crown fires, [7-17], shows that the potential for crown fire initiation and spread does not depend on any single element of the fuel complex, fire weather environment, or topography, but rather from combinations of interrelated variables, including: surface fire intensity, canopy closure, crown density, the presence of ladder fuels, height to base of the combustible crown, crown foliar moisture content, and wind speed. The FCCS crown fire potentials are based on an updated semi-empirical model that describes crown fire initiation and propagation in vegetative canopies based on the work by Van Wagner [2] and Rothermel [3], but updated with additional physical concepts for modelling crown fire behaviour derived from the reformulated Rothermel [4] surface fire equations proposed by Sandberg et al [5]. This crown fire modelling framework is conceptual in nature. It has had limited testing against independent data sets [1], and its use is currently limited to assessing the crown fire potential of FCCS fuelbeds. Additional refinement and verification are needed before the FCCS crown fire model can be considered for wider application. In an earlier effort the FCCS crown fire equations were evaluated against crown fire observations in black spruce (Picea mariana (P. Mill.) B.S.P.) [1]. This paper provides additional evaluation against pine stands characteristic for the eastern Mediterranean. Specifically, a sensitivity analysis was performed for Aleppo pine (Pinus halepensis Mill.) stands in Greece [18, $19]$, and crown fire behaviour was compared with reported modelling results.

\section{FCCS crown fire potentials}

The FCCS crown fire modelling framework ranks the relative potential for crown fire initiation and spread in natural fuelbeds based on a set of actual and inferred characteristics. It draws upon published models and results from crown fire experiments by others, personal observations of crown fires, and conversations with fire managers. This model is intended to objectively assess, on a relative scale, the probability of experiencing torching or active crown fire spread in any FCCS fuelbed. Currently applied crown fire models, [2, 7, 13-17], are largely empirically based and appropriate only when applied to the range of stand structures and fire behaviours observed. While these models are very useful under certain circumstances, they do not provide the broad conceptual 
framework or applicability necessary to compare the crown fire potential within families of dissimilar fuelbeds. For that, the authors sought a more universal approach through the development of this conceptual model.

\subsection{General form}

The general form of the FCCS crown fire potential (CFP) equation is:

$$
C F P=\max (T P, A P)
$$

where $T P$ is the torching potential and $A P$ is the active crown fire potential. Both are dimensionless, ranging in value from zero to $10 . T P$ is the potential for a surface fire to spread into the canopy as single tree or multiple tree torching. If $T P$ is greater than one, then torching is possible. TP is defined as the scaled crown fire initiation term, $I_{C}$ (dimensionless, range zero to 10 ):

$$
T P=c_{T P} \cdot I_{C}
$$

Here, $c_{T P}$ is a scaling function limiting $T P$ to within the range of zero to 10 . Fuelbeds with $I_{C}$ values greater than ten are assigned a $T P$ of ten. Fuelbeds with $I_{C}$ values less than ten are scaled from zero to ten.

$A P$ is the potential for a surface fire to spread into the canopy as an active crown fire. If $A P$ is greater than zero, than active crown fire spread is possible. $A P$ is computed as the scaled product of four terms:

$$
A P=c_{A P} \cdot I_{C} \cdot F_{C} \cdot R_{C}
$$

where $c_{A P}$ is a scaling function that limits $A P$ to a range of zero to 10 (dimensionless), $I_{C}$ is the crown fire initiation term, $F_{C}$ is the crown-to-crown flame transmission term (dimensionless, range zero to one), and $R_{C}$ is the crown fire spread-rate term $(\mathrm{m} / \mathrm{min}$, range one to $>100 \mathrm{~m} / \mathrm{min})$.

Fuelbeds with the product of $I_{C} \cdot F_{C} \cdot R_{C}$ greater than 10 are assigned an $A P$ of 10. Fuelbeds with the product of $I_{C} \cdot F_{C} \cdot R_{C}$ less than 10 are assigned an $A P$ scaled from zero to 10 .

The development of the $I_{C}, F_{C}$, and $R_{C}$ terms are described in Schaaf et al [1] and outlined below.

\subsection{Crown fire initiation term}

Following Van Wagner [2], crown fire initiation is expected when the surface fireline intensity, $I_{B}(\mathrm{~kW} / \mathrm{m})$, exceeds the critical fireline intensity $I^{\prime}(\mathrm{kW} / \mathrm{m})$; that is, when $I_{B} / I^{\prime}>1$. This ratio yields:

$$
\frac{I_{B}}{I^{\prime}}=\frac{16.667 I_{R} t_{R} R}{[C B H(460+25.9 F M C)]^{3 / 2}}
$$


where $I_{R}$ is reaction intensity $\left(\mathrm{kJ} / \mathrm{m}^{2}-\mathrm{min}\right), t_{R}$ is residence time in minutes, $R$ is the forward rate of spread of the fire $(\mathrm{m} / \mathrm{min}), C B H$ is canopy base height $(\mathrm{m})$, $F M C$ is foliar moisture content of canopy fuels (\%), and 16.667 is a constant of proportionality that produces the correct unit conversion (minutes to seconds, among others).

Eqn. (4), expressed in terms of FCCS variables with the residence time set to the inverse of the surface potential reaction velocity, defines the FCCS crown fire initiation term, $I_{C}$ :

$$
I_{C}=\frac{16.667 I_{R . F C C S}\left(1 / \Gamma^{\prime}\right) R_{F C C S . S}}{[(\text { gap } / \text { ladder })(460+25.9 F M C)]^{3 / 2}}
$$

where $\Gamma^{\prime}$ is the potential reaction velocity $(1 / \mathrm{min})$ of surface fuels from Rothermel [4], $R_{F C C S . S}$ is the surface fire spread rate from FCCS (m/min), gap is the physical separation distance between the top of the surface fuel layer and the bottom of the combustible canopy layer $(\mathrm{m})$, and ladder is an heuristically assigned value representing the presence and type of ladder fuels sufficient to act as a vertical carrier of fire to the canopy base (default ladder $=1$, meaning no ladder fuels are present). These terms are all defined in [5]. While the traditional Van Wagner [2] equation bases the calculation of $I^{\prime}$ on $\mathrm{CBH}, \mathrm{FCCS}$ expresses $I^{\prime}$ in terms of the vertical gap between the top of the surface fuelbed layer and the bottom of the combustible canopy layer, with adjustments related to the abundance of combustible ladder fuels. The validity of this modification will be evaluated in future model validation efforts.

$I_{C}$ is evaluated along a continuum ranging from zero to infinity. The higher the $I_{C}$ value, the greater is the potential for initiating a crown fire. This is the same equation set used in [7] except that they structured the equations in a manner that established mid flame wind speed as the principal variable, whereas we have structured the equations to evaluate the initiation potential across a range of fuelbeds with different surface reaction intensities, and rates of spread at a variable benchmark wind speed (default mid flame wind speed is $107 \mathrm{~m} / \mathrm{min}$, or $\sim 6.4 \mathrm{~km} / \mathrm{hr})$.

\subsection{Crown-to-crown flame transmission term}

The FCCS crown-to-crown flame transmission term $\left(F_{C}\right)$ is a dimensionless measure of the capacity to transfer flames through the canopy based on leaf area index $(L A I)$, wind speed, and horizontal continuity of tree crowns. For canopies above some threshold $L A I$, the greater the wind speed the greater the effective horizontal continuity of tree crowns and the greater the crown-to-crown transmission of flames. And the higher the transmission rate, the greater is the potential to sustain an active crown fire. Torching is not affected by the horizontal continuity of tree crowns. 
This new conceptual term is proposed as a replacement for the model originally proposed by Van Wagner [2], which determines whether an active crown fire will occur by comparing the estimated crown fire spread rate with a critical spread rate required to sustain an active crown fire. Although practical and widely used, Van Wagner's model [2] assumes that the canopy is horizontally uniform and continuous. It does not explicitly account for spacing between tree crowns nor does it consider the effect of increasing mid-canopy wind speed in reducing the effective spacing. Moreover, application of the Van Wagner model relies on an estimate of crown-fire spread rate based on a limited correlation developed by Rothermel [3]. The new approach in FCCS is less supported by observations than that developed by Van Wagner [2] and Rothermel [3] but is more physically intuitive. Additional testing of this modelling concept is needed.

The FCCS crown-to-crown flame transmission term, $F_{C}$, is defined as follows:

$$
F_{C}=\left\{\begin{array}{ll}
0, & \text { for } L A I<T L A I \\
\frac{\max (0,[C O V \times W A F]-T C O V)^{0.3}}{([100 \times W A F]-T C O V)^{0.3}}, & \text { for } L A I \geq T L A I
\end{array}\right\}
$$

where $L A I$ is leaf area index $\left(\mathrm{m}^{2} / \mathrm{m}^{2}\right), T L A I$ is threshold $L A I$ for active crowning $\left(\mathrm{m}^{2} / \mathrm{m}^{2}\right), C O V$ is total percentage cover of tree crowns (i.e., percentage canopy cover, or percentage ground area covered by tree crowns) (dimensionless), WAF is a canopy wind speed adjustment factor (dimensionless), and TCOV is threshold percentage canopy cover (dimensionless) required to propagate an active crown fire when $W A F=1(T C O V=40) . T L A I$ was estimated based on Van Wagner's [2] empirical relationship that describes the interaction between canopy bulk density and the minimum spread rate needed to sustain an active crown fire. The resulting formulation is:

$$
T L A I=\frac{C B D_{\text {critical }} \sigma D_{C}}{\rho_{p}}
$$

where $C B D_{\text {critical }}$ is the canopy bulk density $\left(\mathrm{kg} / \mathrm{m}^{3}\right)$ required to sustain an active crown fire, $\sigma\left(\mathrm{m}^{2} / \mathrm{m}^{3}\right)$ is the surface-area-to-volume ratio of foliage elements, $D_{C}$ is the mean canopy depth $(\mathrm{m})$, and $\rho_{\mathrm{p}}$ is the particle density $\left(\mathrm{kg} / \mathrm{m}^{3}\right)$. The development of these terms is described in [1].

Eqn. (6) assumes that a relatively continuous canopy is required for efficient crown-to-crown heat transfer. This validity of this assumption should be evaluated in future field studies. 


\subsection{Crown fire spread-rate term}

The FCCS crown fire spread-rate term, $R_{C}$, is a new, physically-based mathematical approach for estimating the crown fire spread rate using the reformulated Rothermel surface fire spread rate [5], adapted to vegetative canopies. The reformulated Rothermel spread rate is the ratio of a surface-fuel heat source term acting to accelerate the fire spread (numerator), and a heat sink term representing the sum of individual component heat sinks acting to retard the fire spread (denominator). The heat source term includes formulations for reaction intensity, propagating flux ratio, and an acceleration factor for wind. The heat sink terms include various physical fuelbed characteristics, including fuel area index, ignition thickness, heat of pre-ignition, and fuelbed thickness, among others. These terms are described in detail in Sandberg et al [5].

For active crown fires, the combined reaction intensity produced by the flaming combustion at the surface as well as from the flaming canopy fuels drives the forward heating of the fuels and associated fire spread rate. In the FCCS crown fire potential framework, the reformulated Rothermel spread rate has been applied to canopies in a manner similar to its application to the surface fuelbed, with corresponding terms for both the fuel heat source and sink terms based on the unique characteristics of each FCCS fuelbed including a vegetative canopy.

Because of its complexity, a comprehensive description of the crown fire spread-rate term is beyond the scope of this paper. A detailed description is in [1].

\section{Sensitivity analysis}

\subsection{Methods}

The FCCS crown fire equations were tested using data and observations from Aleppo pine (Pinus halepensis Mill.) stands in Greece [18, 19]. In a first comparison, five FCCS pine fuelbeds [20] were selected and evaluated for their potential to represent even- and uneven-aged Aleppo pine stands. The two most representative FCCS fuelbeds were: Fuelbed164 (sand pine forest) and Fuelbed 282 (loblolly pine forest) for even- and uneven-aged stands, respectively (Table $1[21]$ ).

The FCCS models were selected based on the correspondence between critical parameters in crown fire modelling; specifically, crown fuel loading $(C F L)$, crown bulk density $(C B D)$, crown base height $(C B H)$, and surface fuel loading (SFL). Although the $C B H$ of the FCCS stands is somewhat lower than those reported in Table III of the original paper [19], they are comparable to the $C B H$ in typical Aleppo pine stands reported in Table I [19]; specifically, $3.1 \mathrm{~m}$. The two FCCS models were also run against the CFIM/CFIS equations, yielding results that are roughly equivalent to those reported (Table V [19]). 
Table 1: $\quad$ Summary of stand and fuel characteristics for Aleppo pine stands and FCCS fuelbeds.

\begin{tabular}{|c|c|c|c|c|}
\hline & $\begin{array}{c}\text { Even-aged } \\
\text { Aleppo pine }\end{array}$ & $\begin{array}{c}\text { FCCS } \\
\# 164\end{array}$ & $\begin{array}{c}\text { Uneven-aged } \\
\text { Aleppo pine }\end{array}$ & $\begin{array}{c}\text { FCCS } \\
\# 282\end{array}$ \\
\hline $\begin{array}{c}\text { Canopy closure } \\
(\%)\end{array}$ & $76^{[19]}$ & 75 & $69^{[19]}$ & 85 \\
\hline $\begin{array}{c}\text { Stand density } \\
(\mathrm{n} / \mathrm{ha})\end{array}$ & $700^{[19]}$ & 1482 & $697^{[19]}$ & 988 \\
\hline $\begin{array}{c}\text { Stand height } \\
(\mathrm{m})\end{array}$ & $15.7^{[19]}$ & 8.5 & $20.9^{[19]}$ & 19.8 \\
\hline $\begin{array}{c}\text { Crown fuel loading } \\
\left(\mathrm{kg} / \mathrm{m}^{2}\right)\end{array}$ & $1.4^{[19]}$ & 1.1 & $1.4^{[19]}$ & 2.3 \\
\hline $\begin{array}{c}\text { Crown bulk density } \\
\left(\mathrm{kg} / \mathrm{m}^{3}\right)\end{array}$ & $0.18^{[19]}$ & 0.18 & $0.16^{[19]}$ & 0.14 \\
\hline $\begin{array}{c}\text { Crown base height } \\
(\mathrm{m})\end{array}$ & $5.3^{[19]}$ & 2.7 & $3.9^{[19]}$ & 3.0 \\
\hline $\begin{array}{c}\text { Surface fuel load } \\
(\mathrm{t} / \mathrm{ha})\end{array}$ & $2.35^{[18]}$ & 1.95 & $2.35^{[18]}$ & 3.76 \\
\hline
\end{tabular}

In the next step, the two FCCS models were tested for their sensitivity to several key input parameters. Specific input parameters tested were the effects of fire weather class, fuel strata gap $(F S G)$, and flammability of the fuels. Wind speed conversions between the 10 -meter $\left(U_{10}, \mathrm{~km} / \mathrm{hr}\right)$ and mid-flame (1-m wind speed, $U_{l}$ ) wind speeds were assumed a logarithmic vertical wind profile, resulting in $U_{10} \sim 2 * U_{1}$ (similar to the conversion in [1]). The fire weather classes were approximated by varying the $U_{10}$ and estimated fine fuel moisture content (EFFM, \%). Four fire weather classes were tested: low $\left(U_{10}=10, E F F M=12.5\right)$, moderate $\left(U_{10}=20, E F F M=9.375\right)$, high $\left(U_{10}=30, E F F M=6.25\right)$, and extreme $\left(U_{10}=30, E F F M=3.125\right)$. These levels are similar to those reported in CFIM/CFIS model runs for Aleppo pine stands [19]. The effect of FSG (as defined by FCCS) was tested by calculating the physical distance between the top of the stand understory (Table V, [19]), and the $C B H$ (Table III, [19]). The resulting FSG values were then run in FCCS and the effects on potential (crown) fire behaviour evaluated. The specific output variables consisted of TP (eqn. 1), $A P$ (eqn. 2), and the FCCS-based surface and crown fire rates of spread, $R_{F C C S . S}$ and $R_{F C C S . C}$, respectively.

\subsection{Results}

Table 2 summarizes the sensitivity of crown fire perimeters to different fire weather classes, assuming a FSG of 0.9 . This $F S G$ can either be achieved through the physical gap between the $C B H$ and the top of the understory, or, alternatively, through the presence of sufficient ladder fuels to bridge the gap between the two. For both fuelbeds, the $A P$ values are greater than zero, indicating a potential for active crown fire (Table 2). However, in all but the 
extreme weather conditions the fire stays at the surface $(T P<1$; Table 2). Only in Fuelbed 164, with a slightly lower $C B H$, does the fire crown under the extreme fire weather scenario. Fuelbed 282 tends to have somewhat higher fire rates of spread, both in terms of $R_{F C C S . S}$ and $R_{F C C S . C}$ (Table 2), primarily due to higher surface loading and crown fuel loading (Table 1). For both fuelbeds, TP approximately doubles between low and extreme fire weather conditions, whereas $A P$ and $R_{F C C S . C}$ approximately triple in value (Table 2).

Table 2: $\quad$ FCCS-predicted fire behaviour by fire weather class $(F S G=0.9 \mathrm{~m})$.

\begin{tabular}{|c|c|c|c|c|}
\hline & Low & Moderate & High & Extreme \\
\hline \multicolumn{5}{|c|}{ FCCS Fuelbed 164 } \\
\hline$T P$ & 0.7 & 0.8 & 0.9 & 1.3 \\
\hline$A P$ & 3.3 & 4.3 & 7.3 & 10.0 \\
\hline Fire type & Surface & Surface & Surface & Active crown \\
\hline$R_{\text {FCCS.S }}(\mathrm{m} / \mathrm{min})$ & 1.8 & 1.9 & 2.1 & 2.5 \\
\hline$R_{\text {FCCS.C }}(\mathrm{m} / \mathrm{min})$ & 1.8 & 1.9 & 2.7 & 3.1 \\
\hline \multicolumn{5}{|c|}{ FCCS Fuelbed 282 } \\
\hline \multicolumn{7}{|c|}{} & 0.5 & 0.5 & 0.6 & 0.9 \\
\hline TP & 3.4 & 7.8 & 10 & 10 \\
\hline AP & Surface & Surface & Surface & Surface \\
\hline Fire type & 2.2 & 2.3 & 2.5 & 3.1 \\
\hline$R_{\text {FCCS.S }}(\mathrm{m} / \mathrm{min})$ & 2.4 & 4.8 & 7.3 & 7.7 \\
\hline$R_{\text {FCCS.C }}(\mathrm{m} / \mathrm{min})$ &
\end{tabular}

Figure 1 summarizes the sensitivity of the torching potential, $T P$, to the fuel strata gap, FSG. The results indicate that Fuelbed 164 (circles) consistently has higher $T P$ values than Fuelbed 282 , likely due to the lower $C B H$ and $R_{F C C S . S}$. Furthermore, consistent with Table 2, these stands only crown when the FSG is relatively low $(<1 \mathrm{~m})$, and under extreme fire weather conditions.

Lastly, the sensitivity of the crown fire parameters to the reaction intensity was tested. Reports in the literature suggest that Aleppo pine stands are considerably more flammable than typical fuels in North America [22]. Based on this observation, fire behaviour for a North American fuel model \#10 (timber litter, heavy dead-and-down fuel loading) was increased four times to better represent the more flammable fuel conditions in Mediterranean Aleppo pine stands [22]. Following this lead, the reaction intensity in FCCS ( $I_{R}$, eqn. 4) was also increased four times. With this adjustment, both stands have the potential to actively crown in all four fire weather classes (data not shown). Moreover, $R_{F C C S . C}$ increased four-fold to ranges of from 3 to $12 \mathrm{~m} / \mathrm{min}$, and from 10 to 30 $\mathrm{m} / \mathrm{min}$, for Fuelbeds 164 and 282, respectively (Figure 2). $R_{F C C S . S}$ values ranged from 7 to $12 \mathrm{~m} / \mathrm{min}$ depending on fire weather class, but with much smaller differences between fuel models $(<20 \%)$. 


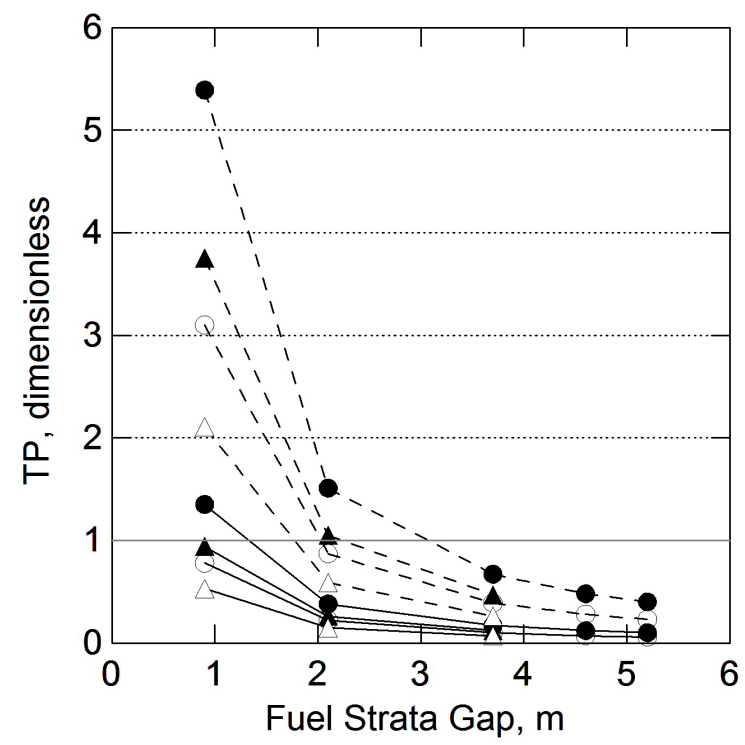

Figure 1: Torching potential $(T P)$ as a function of the fuel strata gap, the FCCS fuelbed number, fire weather class, and fire intensity adjustment factor. FCCS Fuelbed 164 (circles) and 282 (triangles) are shown for moderate fire weather (open symbols) and extreme fire weather (closed symbols). TP values without the factor-of-4 adjustment for $I_{R}$ are shown as solid lines and with the factor-of-4 adjustment as dashed lines. TP values greater than 1 indicate the potential for crown fire, either active or passive.

\section{Conclusions and recommendations}

The FCCS crown fire potential equations yielded crown fire spread rates ranging from 2 to $7 \mathrm{~m} / \mathrm{min}$ for the moderate to extreme fire weather classes, respectively (see Table 2). These crown spread rates are similar to those reported for typical Aleppo pine stands in Greece (1 to $5 \mathrm{~m} / \mathrm{min}$ [18]), and observations in Maritime pine (Pinus pinaster) stands in Portugal (2 to $4 \mathrm{~m} / \mathrm{min}$ [23]). Furthermore, in the moderate fire weather class, the FCCS crown fire spread rates (2 to $5 \mathrm{~m} / \mathrm{min}$ ) compared favourably with observed crown fires in Maritime pine reported in [15, Table 4] under similar fire weather condition; specifically, 2 to $4 \mathrm{~m} / \mathrm{min}$.

Adjusting for the differences in flammability between Aleppo pine and fuels in North America [22] resulted in an increase in the crown fire potentials, $T P$ and $A P$, as well as the predicted $R_{F C C S . C}$ values (Figures 1 and 2). The resulting $R_{F C C S . C}$ values are considerably lower than those reported for CFIM/CFIS model runs for these stands [19]. However, in a comparison of models, Scott [24] reported that CFIM provided high estimates of both crown fire initiation thresholds and crown fire spread rates. 


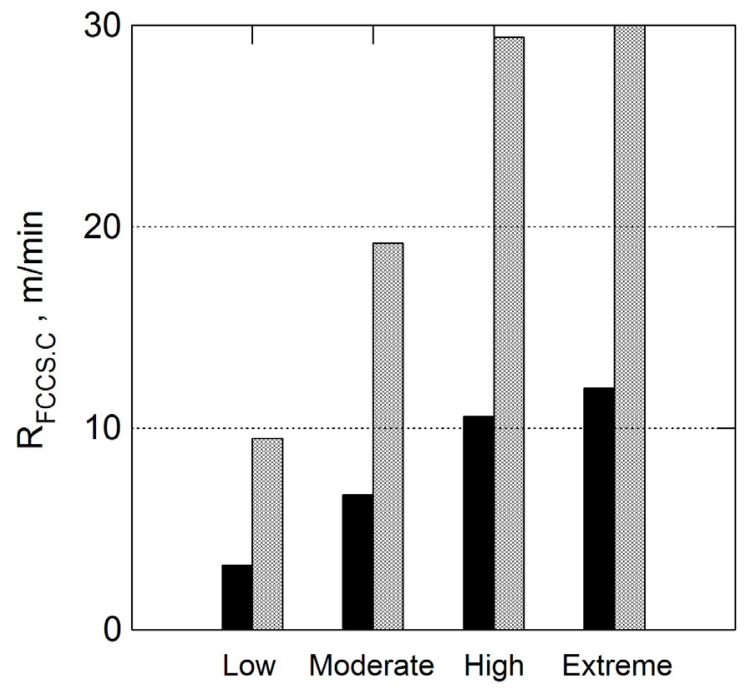

Figure 2: $\quad R_{\text {FCCS.C }}(\mathrm{m} / \mathrm{min})$ for FCCS Fuelbeds 164 (black) and 282 (hatched) as a function of fire weather class, assuming a four-fold increase in flammability.

The onset of crown fire in FCCS, indicated by $T P$ and $A P$, was shown to be dependent on several factors, including: fire weather class, the presence of surface and ladder fuels, $C F L$, and $C B D$. These findings are consistent with recommendations to reduce wildfire effects in Mediterranean Maritime pine stands, such as reducing surface fuel loading, removal of ladder fuels, and reducing crown fuel loading [25]. In FCCS, the crown fire predictions are influenced proportionately by the adjustment factor for reaction intensity. While we used an adjustment factor of 4, adjustment factors of 1.5 to 2 are sufficient to initiate crown torching in the modelled FCCS fuelbeds.

The good correspondence with observations and modelling results in Aleppo pine suggest that the FCCS crown fire potentials might be a useful tool for fire managers in the Mediterranean region to consider when evaluating the relative behaviour of crown fires in vegetated canopies.

\section{References}

[1] Schaaf, M.D., M.D. Schreuder, Sandberg, D.V., and Riccardi, C.L., Fire potential rating for wildland fuelbeds using the Fuel Characteristic Classification System, Can. J. For. Res. 37, pp. 2464-2478, 2007.

[2] Van Wagner, C.E., Conditions for the start and spread of crown fire, Can. J. For. Res. 7, pp. 23-34, 1977.

[3] Rothermel, R.C., Predicting behavior and size of crown fires in the Northern Rocky Mountains, USDA For. Serv. Res. Pap. INT-438, 1991. 
[4] Rothermel, R.C., A mathematical model for predicting fire spread in wildland fuels, USDA For. Serv. Res. Paper INT-115, 1972.

[5] Sandberg, D.V., Riccardi, C.L., and Schaaf, M.D., Reformulation of Rothermel's wildland fire behavior model for heterogeneous fuelbeds, Can. J. For. Res. 37, pp. 2438-2455, 2007.

[6] Ottmar, R.D., Sandberg, D.V., Riccardi, C.L., and Prichard, S.J., An overview of the Fuel Characteristic Classification System (FCCS) quantifying, classifying, and creating fuelbeds for resource planning, Can. J. For. Res. 37, pp. 2383-2393, 2007.

[7] Scott, J.H., and Reinhardt, E.D., Assessing crown fire potential by linking models of surface and crown fire behavior. USDA For. Serv. Res. Pap. RMRS-RP-29, 2001.

[8] Stocks, B.J., Alexander, M.E., and Lanoville, R.A., Overview of the International Crown Fire Modelling Experiment (ICFME), Can. J. For. Res. 34, pp. 1543-1547, 2004.

[9] Butler, B.W., Finney, M.A., Andrews, P.L., and Albini, F.A., A radiationdriven model for crown fire spread, Can. J. For. Res. 34, pp. 1588-1599, 2004.

[10] Cruz, M. G., Alexander, M. E., and Wakimoto, R. H., Definition of a fire behavior model evaluation protocol: A case study application to crown fire behavior models. In: Fire, Fuel Treatments, and Ecological Restoration: Conference proceedings. USDA Forest Service Proceedings RMRS-P-29, pp. 49-67, 2003.

[11] Cruz, M.G., Alexander, M.E., and Wakimoto, R.H., Assessing the probability of crown fire initiation based on fire danger indices, For. Chron. 79, pp. 976-983, 2003.

[12] Cruz, M.G., Alexander, M.E., and Wakimoto, R.H., Modeling the likelihood of crown fire occurrence in conifer forest stands, For. Sci. 50, pp. 640-658, 2004.

[13] Cruz, M.G., Butler, B.W., Alexander, M.E, and D.X. Viegas, Development and evaluation of a semi-physical crown fire initiation model. In: Viegas, D.X. (Ed.), Proceedings of $V$ International Conference on Forest Fire Research, Millpress Sci. Publ., Rotterdam, Netherlands, CD-ROM, 2006.

[14] Cruz, M.G., Butler, B.W., Alexander, M.E, Forthofer, J.M., and Wakimoto, R.H., Predicting the ignition of crown fuels above a spreading surface fire, Part I: model idealization, Int. J. Wildl. Fire. 15, pp. 47-60, 2006.

[15] Cruz, M.G., Butler, B.W., and Alexander, M.E., Predicting the ignition of crown fuels above a spreading surface fire. Part II: model evaluation. Int. J. Wildl. Fire. 15, pp. 61-72, 2006.

[16] Alexander, M.E., Cruz, M.G., and Lopes, A.M.G., CFIS: A software tool for simulating crown fire initiation and spread. In: Viegas, D.X. (Ed.), Proceedings of $V$ International Conference on Forest Fire Research. Millpress Sci. Publ., Rotterdam, Netherlands. CD-ROM, 2006.

[17] Alexander, M.E., and Cruz, M.G., Evaluating a model for predicting active crown fire rate of spread using wildfire observations, Can. J. For. Res. 36, pp. 3015-3028, 2006. 
[18] Dimitrakopoulos, A., Mediterranean fuel models and potential fire behavior in Greece, Int. J. Wildl. Fire 11, pp. 127-130, 2002.

[19] Mitsopoulos, I., and Dimitrakopoulos, A., Canopy fuel characteristics and potential crown fire behavior in Aleppo pine (Pinus halepensis) forests, Ann. For. Sc. 64, pp. 287-299, 2007.

[20] FCCS, version 2.0, www.fs.fed.us/pnw/fera/fccs/

[21] Riccardi, C., Ottmar, R., Sandberg, D., Andreu, A., Elman, E., Kooper, K., and Long, J., The fuelbed: a key element of the Fuel Characteristic Classification System, Can. J. For. Res. 37, pp. 2394-2412, 2007.

[22] Carmel, Y., Shlomit, P., Jahashan, F., and Shoshany, M., Assessing fire risk using Monte Carlo simulations of fire spread, For. Ecol. and Mgmt. 257, pp. 370-377, 2009.

[23] Fernandes, P., Loureiro, C., and Botelho, H., Outcomes of a high-intensity experimental fire in a maritime pine stand. In: Proceedings of the International Scientific Workshop on "Forest Fires in the Wildland-Urban Interface and Rural Areas in Europe: An Integral Planning and Management Challenge." May 15-16, 2003, Athens, Greece, 2003.

[24] Scott, J., and Burgan, R., Standard fire behavior fuel models: a comprehensive set for use with Rothermel's surface fire spread model, USDA Forest Service General Technical Report RMRS-GTR-153, 2005.

[25] Fernandes, P., and Rigolot, E., The fire ecology and management of maritime pine (Pinus pinaster Ait.), For. Ecol. and Mgmt. 241, pp. 1-13, 2007. 